\title{
Creating a new environmental business: Early struggles and the creation of a self-sustaining entity
}

\author{
William P. Racine \\ School of Business and Leadership, Malone University, Canton, Ohio, USA \\ Corresponding Author: e-mail: wracine@malone.edu or williamracine@ymail.com \\ Tel. +1-330-494-0905, Fax +1+330-494-1650
}

\begin{abstract}
This phenomenological research is an exploration of the initial years of the new venture creation process of environmental entrepreneurs. The objective of this research was to explore the retrospective understanding of these scientists-turnedentrepreneurs as they experienced the transition from scientist to businessperson and employee to entrepreneur. Twenty environmental entrepreneurs answered the research question: What is their retrospective assessment of the early struggles and lived experiences leading to firm establishment as they engaged in the new venture creation process? This study determined that the experience of starting a new venture is distinct from the establishment of self-sustaining new venture. Each experience displays a discrete essence as the scientist navigates the new venture creation process.
\end{abstract}

Keywords: Entrepreneurship, Environmental Entrepreneurs, Phenomenology, New Venture Creation

\section{Introduction}

The start-up of a new entrepreneurial venture is a precarious and personal proposition. One-third of businesses voluntarily close their doors within the first 4 years and another third fail within this same period (Headd, 2002). The knowledge that the personal risks are high and the failure rates frequent is commonplace. Even so, many nascent entrepreneurs venture forth and continue to establish new businesses in a variety of disciplines. A continued pool of founders willing to engage in these new ventures is vitally important to the domestic economy.

The importance lies in job creation, productivity, and potential for future growth. New entities with only one employee, which new ventures oftentimes are, account for 75 percent of all businesses in the U.S. (Davis, Haltiwanger, \& Jarmin, 2008). Entities with multiple employees that are less than four years into their new venture contribute $20 \%$ to the gross domestic revenue of the United States and represent approximately $28 \%$ of all firms (Davis, et al., 2007). New scientific new ventures are a subset of these values, those that occur outside of academia, an even smaller subset, and environmental ventures, fewer still.

The creation and maintenance of new environmental endeavors receive the highest levels of attention in the United States. President Barack Obama stated that his presidency would create millions of new jobs by strengthening environmental policies and fostering an expansion of markets for environmental products and services (Schuster, 2008). This information would suggest that the environmental marketplace is ripe for opportunity and expansion. However, the dearth of environmental professionals capable of managing the myriad of environmental issues is inadequate (Hochberg \& Cohen, 2006). In light of this information, and perhaps because of it, some environmental scientists seek to market their innovations, products, and services within the competitive marketplace.

An assessment of the start-up experience of the environmental entrepreneur as they transition from scientist to businessperson and employee to entrepreneur is the subject of this research. This phenomenon influences how these individuals experience the new venture creation process and their actions leading to success. Twenty environmental entrepreneurs answered the research question - What is their retrospective assessment of the early struggles and lived experiences leading to firm establishment as they engage in the new venture creation process? A qualitative exploration in the Husserlian tradition was used to assess their lived 
experience. This information enhances the existing body of knowledge of scientific entrepreneurship and provides salient information to those engaging in this endeavor.

\section{Background}

The unique nature of scientists has long been discussed. Plato remarked that, "Scientists are people of very dissimilar temperaments doing different things in very different ways. Among scientists are collectors, classifiers, and compulsive tidiers-up; many are detectives by temperament and many are explorers; some are artists and others artisans” (Plato, trans. 1982, p. 116). Maslow (1954, p. 2) stated that scientists possessed “... cognitive needs for sheer knowledge (curiosity) and for understanding (the philosophical, theological, and value-system-building)..." He went on to suggest what he termed, "impulses to beauty, symmetry, and possibly to simplicity, completion, and order..." (Maslow, 1954, p. 2). Such notables as Benjamin Franklin, Alexander Graham Bell, Thomas Edison, George Washington Carver, and countless others are exemplars of this phenomenon. Yet, with a rich and noteworthy history, the social science research into scientific entrepreneurship remains scant.

The historic research progressed similar to that of other forms of entrepreneurship in that the initial attempts were to classify the specific characteristics of these individuals. This early scholarly work proved more descriptive than explanatory. The research attempted to discern the differences in the traits, tendencies, behaviors, and actions of these individuals with some success. Researchers also documented the specific problems for new scientific ventures including ineffectual business management causing organizational problems (Ahn, 2008), the inability to grow (Kenney, 1986), and insufficient business education and training (Bell \& McNamara, 1991). This research suggests that scientific entrepreneurs witness specific business related issues and that these influence their ability to sustain the requisite start-up activities (Danielson, 1960; Roberts \& Wainer, 1971; Litvak \& Maule, 1973; Samsom, 1990). Yet, comparatively little is known about scientific entrepreneurs, and even less about the environmental entrepreneur.

Environmental scientists assist industry with regulatory compliance and environmental management in the marketplace. Some of these environmental scientists have decided to enter the world of business, exploit their discoveries, and commercialize their professional knowledge inside the competitive industrial framework. Most have little entrepreneurial experience. The success of environmental entrepreneurial endeavors is vitally important given the governmental emphasis for a more entrepreneurial economy, the current prominence of environmental stewardship, and the social insistence on revitalizing aged industrial properties.

These scientists will face challenges in the first four years of their venture that are only vaguely understood because the current appreciation of the experience is incomplete. Some researchers believe that certain benefits accrue to the scientist that may not be accessible to other entrepreneurial endeavors. Gaebler (2009) states, "scientific entrepreneurs have an inherent advantage over other entrepreneurs. They are closer to the future than the rest of us. That proximity to the cutting edge gives them the opportunity to start businesses based on science that are truly breakthrough in nature.” Researchers have contributed limited knowledge about the start-up experience of scientists and their transition from employee to entrepreneur and scientist to businessperson.

A better understanding of the phenomenon necessitates further study because of its importance in the modern day and comparatively little peer-reviewed research has been dedicated to these scientific businesspersons, their experiences, their motivations, and the commercialization of their work. Specifically, the first four years, the acid test for entrepreneurial ventures, is the focus of this research. This research intends to explore the existing business and entrepreneurship literature relative to this phenomenon, describe the lived experience of these scientists-turned-entrepreneurs in the early years, and provide a salient understanding of the environmental entrepreneur's agency in the new venture creation process.

\section{Theoretical Review}

Early scholarly work related to scientific entrepreneurs most often focused on the options available to scientists within the university setting. Some research presents a detailed discussion of the evolution of a discovery from the university, where most discoveries begin, through exploitation, within the academic framework. It is in this area where the modern discussion of the scientist-turned-entrepreneur begins.

\subsection{The Origins of Scientific Entrepreneurship Research}

The early work suggested that exporting scientific discoveries to industry was hindered by the unique alternatives available to the university scientist (Bell \& McNamara, 1991; Litvak \& Maule, 1973, Danielson, 1960). These hindrances were in the form of fellowships, scholarships, grants, and endowments designed to keep the scientist at the university and provided a significant filtering mechanism in exporting the new venture creation process beyond the walls of the university (Samsom, 1990). Choosing to stay within the university setting enabled scientists to avoid the difficulties of an external entrepreneurial venture while still receiving some of the benefits. Early social science researchers sought to document the various facets of risk, ambiguity, and scientific exploitation within this setting. Because of this, little scholarly literature is available on scientific entrepreneurship outside of the university setting prior to the early 1980’s. 
In the late 1980's researchers sought to differentiate the subset of entrepreneurial scientists from other entrepreneurs. Karel Samsom looked specifically at new ventures started by scientists in the business context by studying chemists, biologists, and other scientists-turned-entrepreneurs to discover how they plan and manage their new venture outside of the academic setting. Samsom (1990) confirmed that scientists have fundamental cultural and behavioral differences that influence the new venture creation process. This suggests that scientists-turned-entrepreneurs have different characteristics that frame their engagement in the entrepreneurial process outside of the university.

Various other studies, in the early stages of understanding the phenomena of the scientist-turned-entrepreneur, have focused on just this issue. Bell and McNamara (1991) presented a study designed to assess scientific start-up ventures both within the university setting and as autonomous ventures. They suggested that the problems with scientist-led entrepreneurial ventures outside of the university setting usually involve management insufficiency, monetary problems, and technology flaws in getting a product to market (Bell \& McNamara, 1991).

Other social science researchers too have considered the issues of scientist-lead business ventures and have precipitated the notion that endeavors outside the academic setting can be problematic. These problems include a potential decrease in innovation (Kenney, 1986), ineffectual business management (Ahn, 2008), inability to grow (Kenney, 1986), collaboration inefficiencies (Niemi, 1993), and insufficient business education and training (Bell \& McNamara, 1991). This research suggests that scientific entrepreneurs witness specific business related issues and that these influence their decision to engage in start-up activities outside the university setting.

\subsection{Characteristics of the Scientific Entrepreneur in Business}

Quantitative studies have been conducted on those scientists who have decided to pursue opportunities outside of the academic setting. Like much of the entrepreneurship research in the mid-twentieth century, researchers into scientific entrepreneurship focused their collective attention on the issue of characterizing personality traits. Personality traits such as independence, control, self-sufficiency, and autonomy are consistent with McClelland's (1961) findings. Yet, research into the general differences in the attributes of scientific entrepreneurs helped further the conceptualization of these individuals.

Understanding that the basic general attributes of scientific entrepreneurs is important to the discussion of scientific entrepreneurship, Danielson studied 277 scientists and engineers in industrial settings. Danielson (1960) reported that these individuals perceived themselves to possess certain characteristics that are not common to all entrepreneurs. Scientific entrepreneurs exhibit an elevated level of persistence, more objectivity and skepticism, higher levels of responsibility, increased creativity, dedication to fundamental scientific knowledge, and a higher awareness of broader, more ethereal goals (Danielson 1960). This suggests that scientific entrepreneurs are not readily interchangeable with other entrepreneurs in terms of these traits.

Other studies suggest the educational and cultural development of scientists precipitate a certain set of characteristics, which might influence their actions. Those characteristics, which were shown to be the most significant included:

1. Scientists have differences in perceptions, brought about by cultural and educational differences related to planning and goal attainment (Roberts \& Wainer, 1971),

2. Scientists demonstrate more objectivity (Litvak \& Maule, 1973),

3. Scientists view longer and broader contexts for their work versus managers, which are shorter-goal oriented (Dubinskas, 1985), and

4. Scientists perceive the greater goal of advancing scientific knowledge over organizational loyalty and success (Samsom, 1990).

The contention by these researchers is that the educational and cultural development of scientists produces a different, or possibly extended, set of characteristics relative to non-scientific entrepreneurs. Because of this, researchers began to explore the tendencies exhibited by the scientist once the decision was made to engage in an entrepreneurial venture.

\subsection{Common Tendencies of the Scientific Entrepreneur}

Researchers have found that certain tendencies are associated with scientific entrepreneurs. Many of these tendencies are found to be specific to these individuals by virtue of their education, development, and interests (Dubinskas, 1985). An exploration of these tendencies assists with the fundamental conception of the scientist-turned-entrepreneur.

Scientific entrepreneurs have a tendency to attach a greater weight to technology development than to commercialization. Samsom (1990) stated that this is because of their desire to see their innovation contribute to the common good. This implies a tendency to contribute to society versus other more common motivations of a business venture, such as financial incentives. Samsom's understanding might explain Dubinskas' (1985) discussion of goal context and Roberts and Wainer's (1971) discussion of goal orientation.

In addition, scientific entrepreneurs are adept at discerning a scientific opportunity over other non-entrepreneurial scientists (Dubinskas, 1985). The tendency for these individuals to perceive exploitable scientific innovations is consistent with 
Venkataraman's (1997) findings that this skill is contingent upon their entrepreneurial insights, skills, and aptitudes, scientific or otherwise. Cooper, Folta, and Woo (1995) suggested that the scientist's individual cognition styles evaluate information in a specific context. This implies the scientific entrepreneur has a greater tendency and ability to discern an opportunity from a scientific innovation, more so than non-entrepreneurial scientists.

Burns and Stalker (1966) and Dubinskas (1988) propose scientists-turned-entrepreneurs have a tendency to see the laws of nature, and therefore the contribution to knowledge, as being superior to any specific organizational goal. Moreover, the scientific entrepreneur sees development of any innovation as a part of a life-long discovery process beyond merely exploiting its benefits. Resultantly, Burns and Stalker (1966) suggested that many scientific entrepreneurs appear to be semi-detached from the venture or organization although profoundly committed to the aspect of scientific knowledge and discovery.

Samsom (1990) agreed that scientific entrepreneurs emphasize their belief in working for a higher cause. Because of this, scientific entrepreneurs have a greater tendency to control their technology as it transferred through the invention to innovation to exploitation lifecycle. This need for control and directedness toward a higher cause, according to Samson (1990), results in a greater tendency to overrate the importance of science in the new venture creation process. These tendencies are reflected in the later behaviors of the scientific entrepreneur.

\subsection{Behaviors of the Scientific Entrepreneur}

Certain behaviors appear to be consistent among scientist-founded enterprises. Lewin (1935) conceptualized behaviors as the interaction between a person and their environment. Resultantly, behaviors affect the success of the new venture. In fact, what scientists-turned-entrepreneurs do might be more descriptive and more salient than who they are or what tendencies they portray. This Lewinian framework influences the scientist's new venture creation process.

Several behaviors characterize these individuals in the new venture creation process. First, scientists are more likely to become engaged in scientific businesses (Samsom, 1990). This appears to be a basic premise but given the significant amount of overlap between the general characteristics of scientific and non-scientific entrepreneurs, this premise cannot be overlooked. Second, commercialization typically is brought about by the scientist (Samsom, 1990), at least initially. Notwithstanding later changes in the administration of the venture, the control over the fate of the innovation rests upon the shoulders of the scientist. Third, scientific entrepreneurs consider the aspects of business education, management expertise, accounting, and training to be of secondary importance and behave accordingly (Litvak \& Maule, 1973; Sindermann, 1982). This could present a possible connection to attrition or venture failure rates.

Other behaviors usually bounded by the aforementioned concepts, influence the new venture. This includes business operations where the scientist is more obstinate when it comes to managerial or business-related change (Sindermann, 1982). This is also reflected in the organizational design where scientist-lead organizations are less reflective of progressive practices than other executive-lead organizations (Moss-Kanter, 1989). Venture financing, marketing, and planning, are also less developed in the typical scientist-lead organization (Litvak \& Maule, 1973). These behaviors suggest the scientist, while enmeshed in research since education, does not thoroughly engage in research in the business aspects of creating, operationalizing, and sustaining the new venture.

\subsection{Commercialization by the Scientist-Turned-Entrepreneur}

A discussion of the scientist-turned-entrepreneur must involve the characterization of what the literature suggests about these individuals after the decision has been made to exploit the venture commercially. The role of the scientist changes as does the duties and responsibilities for the survival and success of the new venture. These duties and responsibilities are required of the entrepreneur and assist with the understanding of the scientist-turned-entrepreneur.

The data confirms the requirement for the continued involvement of the scientist (Zucker, 1998; Stuart \& Ding, 2006; Phillips \& Zuckerman, 2001). The scientist and the innovation cannot be divorced, at least initially, as easily as might occur in other forms of entrepreneurship. The scientist embodies the product, not unlike a brand provides meaning, and cannot easily be duplicated.

Beyond a mere involvement, Zucker (1998) suggested that scientists must maintain a key role in both the development of the technology as well as the commercialization of the technology. To some in academic circles, these scientific entrepreneurial endeavors represent a loss to the scientific community where entrepreneurial scientists are perceived as "selling-out" in pursuit of financial rewards (Zucker, 1998). Yet, the data contraindicates this notion. Scientists actually publish more (an indicator of their continued scientific success) during the creation of their entrepreneurial venture than before or after (Zucker, 1998). This begets other discoveries thereby advancing knowledge and permitting further entrepreneurial venture creation.

Exploration of the post-product introduction, while minimally researched, suggests that these scientific entrepreneurs begin to recognize all functions as important to the success and vitality of the new venture. The understanding of issues that were heretofore considered secondary, are seen as important including allocation of resources, accounting, financial management, human resources, training, and business expertise (Samsom, 1990). Given this, it appears the continued learning of the scientific entrepreneur is not mitigated but enhanced by the commercialization process. 
The existing body of research has been eclectic. The data, while descriptive, does not fully divulge the essence of the experience for current and nascent scientists with regard to their lived experiences. This is especially interesting given the changes brought about by such an action. For example, the individual exchanges the security associated with being an employee for that of an entrepreneur. They also exchange the scientific culture for that of a competitive business. They also take on additional risk, typically have less business experience, and have less access to capital. Building a new venture might be conceived of as challenging and rewarding but the risks are well known and the failure rates too have been well documented. Therefore, the lived experience of these individuals is crucial to understanding the meaning that their experience brings to other nascent scientific entrepreneurs.

\section{Research Question, Philosophy and Design}

An assessment of the lived experience of environmental entrepreneurs will impart meaning to the new venture creation process. There is an unrealized potential and a gap in the literature in this regard. The research question for this proposal is - What is the retrospective assessment of the early struggles and lived experience leading to firm establishment of environmental entrepreneurs as they engage in the new venture creation process? This research endeavored to answer that question.

Phenomenology is an appropriate platform for exploring the lived experience and uncovering the essence of a phenomenon (Creswell, 2007). In the search for exploratory information, Husserl (1948) suggested that researchers not seek quantitative descriptions but rather return to the meaning of the experience or phenomenon to humans. The human experience of a phenomenon is the true reality in the context of the human mind. Therefore, it is important to seek the essence and nature of the experience from the perspective of those successful scientific entrepreneurs that have started and sustained it. This phenomenological inquiry used interviews to capture the abundant meanings resident in the experience

Interviews were conducted with successful environmental scientists that founded their own environmental ventures. The objective of these interviews was to understand the events that they retrospectively reasoned to be important to the start-up of their new ventures. Prior to conducting personal interviews, a prequalification questionnaire was provided to each founder to determine that they could provide a meaningful answer to the research question. The rationale, as Kvale (1996) suggests, is that interviews capture a multitude of views about a phenomenon in a manifold social perspective.

Purposeful sampling was used to select founding environmental entrepreneurs to answer the research question. Given the potential population, demographics, and the research methodology, a sample size of 20 was deemed appropriate for this study. Sample size is not as ratio-dependent as in quantitative assessments therefore; the exact number is less crucial to qualitative assessments (Creswell, 2007). The criteria for participation included those successful environmental entrepreneurs in Ohio that are still in the same environmental business they founded, had operated their businesses profitably for, at least, the last ten years, and were unfamiliar with the researcher before the interview. Table 1 presents the participant group.

Table 1. The Participant Group

\begin{tabular}{|l|c|c|c|}
\hline Discipline & Service Rendered & Business Form & Longevity \\
\hline Air Pollution Control (1) & Consulting & LLC & 12 years \\
\hline Asbestos Abatement (2) & Contractor & C-Corp & $17 / 26$ years \\
\hline Compliance Professionals (2) & Consulting & LLC/S-Corp & 20-21 years \\
\hline Drilling Services (1) & Contractor & C-Corp & 14 years \\
\hline Emergency Response (1) & Contractor & C-Corp & 21 years \\
\hline Geological/Biological Services (3) & Consulting & LLC/S-Corp & $16-20$ years \\
\hline Hazardous Waste Remediation (2) & Contractor & C-Corp & $14 / 15$ years \\
\hline Property Transfer Site Assessments (2) & Consulting & S-Corp & $12 / 17$ years \\
\hline Radioactivity/Health Physics (1) & Consulting & S-Corp & 16 years \\
\hline Soil/Groundwater Remediation (3) & Contractor & C-Corp & $15-19$ years \\
\hline Wetlands Assessment (2) & Consulting & LLC/S-Corp & $18 / 21$ years \\
\hline
\end{tabular}

These ventures produce between $\$ 250,000$ and $\$ 10$ million in annual revenue and employ between 2 to 300 personnel. The objective of the interviews was to extrapolate and present emergent themes representative of the phenomenon.

Emergent themes are an assemblage of elements that are unique to the participant community and relate across the expressed discourse of the group. The interviews produced over 250 pages and 4,000 lines of transcribed text. Analysis of this data unveiled themes that were coded and analyzed using $\mathrm{NVivo}^{\mathrm{TM}}$ software. Although many perspectives were expressed and were given equal weight, certain elements represented themes that emerged from the research. Some of these themes represent viewpoints given by only a few of the participants while others are more pervasive across the group. Themes are presented so that a thorough representation of the experience can be understood. 
Triangulation was used to minimize researcher bias, assist with data validity, and assure credible data reduction. According to Miles and Huberman (1994, p. 266), triangulation is, “... used to show that independent measures agree or, at least, do not contradict each other.” The themes presented in this section were checked using peer review or, according to Denzin (1978), researcher triangulation. After application of pseudonyms to assure confidentiality, a colleague, who was not a part of the data set or involved with the data acquisition, evaluated the thematic representations to consider alternative meanings or additional themes. This is consistent with Creswell and Miller (2000, p. 126) where, “...researchers search for convergence among multiple and different sources of information to form themes or categories in a study." This mode of triangulation helps expose missing themes and confirm the thematic representations.

\section{Data presentation}

The data derived from this research considered the early struggles of the new venture creation experience through the establishment of the firm. In most cases, this time period comprised a 12-48 month time period. The data presents different themes for the early struggles of a new entity versus the actual attainment of a self-sustaining entity.

\subsection{Emergent Themes in the Early Struggles of the Lived Experience}

The data suggests that five categorical themes are resident in the lived experience that comprises the early years of the new venture creation process. These themes are relatively consistent across the participant population and serve to provide an apt description of the early evolution of the new venture creation experience. These themes are interesting since many of the entrepreneurs foresaw such hardships prior to realizing the experience. Yet, the gravity of the decision has not come to fruition and the consequence of the difficulties served to create lasting impressions that formed their conceptualization of the experience.

\subsubsection{Theme 1: Acculturation}

The first theme resident in the early evolution of the new venture creation experience is a realization of the difficulties described as cultural adjustments, or acculturation, in the transition from scientist to businessperson and employee to entrepreneur. Many statements suggested that family, friends, employees, former co-workers, former superiors, or clients explicate various rationales as to why the decision was ill conceived, uninformed, or disadvantageous. This suggests the acceptance of the new role undertaken by these entrepreneurs was not readily accepted. These statements included, "I was not accepted at first by my peers" or "My friends thought I was mistaken." Several of these entrepreneurs stated their surprise at this aspect of the new venture creation process. Many of the entrepreneurs suggested their surprise was because they feel unchanged by saying, "I felt as if I was still the same person" or "Only just my position with a company had changed, not the type of work I do." The entrepreneurs admitted this disenfranchisement was disappointing but most suggested this acted as a fulcrum to fortify their resolve.

\subsubsection{Theme 2: The Realization of Personal and Physical Difficulties}

The second theme resident in the early evolution of the new venture creation experience is a realization of the personal and physical difficulties wrought by the new venture creation process. Many statements described the mental anxiety, emotional angst, sleepless nights, nervousness, and uncertainty resulting from the establishment of their new ventures or the removal of the security associated with employment by others. This cognitive dissonance appeared in a variety of forms among the participants including, "I stared out the window and wondered what I had done," "I lost a lot of sleep in those early years," and, "I realize now that there is a lot to be said for knowing you have a steady paycheck every two weeks." The angst spilled-over into their relationships as evidenced by statements such as, "I began to argue more with my spouse," or "I became edgy with my kids," and, "I watched our savings dwindle to nothing and this caused a lot of anxiety." Most readily owed this to the tribulations of the experience. This theme was relatively pervasive among the group. The gravity of the situation lasted for various time periods and to varying degrees. Only two suggested this part of the entrepreneurial experience was absent or negligible. Most of these entrepreneurs agreed that they underestimated the toll that the personal and physical difficulties associated with the new venture creation process would extract.

\subsubsection{Theme 3: Changing Self-Perceptions}

The third theme in the early evolution of the entrepreneurial process is the attenuation of self-perception. Many statements suggested that most entrepreneurs experienced a recognition that their doubts and fears of failure might become realized. The dubiousness of their decision to engage in the new venture creation process was present in statements like, "I felt miserable and all alone" or "...this was a low point...," and this indicated their second thoughts. Most used their historic position as a reference point in saying, "This was a big change from my corporate life" or "This was different from my old job where..." There was an acknowledgment that the experience of entrepreneurship, at this point, was inferior to their previous reality. This theme did not 
arise in cases where the participant believed the new venture creation process was unproblematic. This resulted in the entrepreneur's reflexive appraisal that they had entered into a decision that had fundamentally changed their lifeworld.

\subsubsection{Theme 4: Managerial Difficulties}

The fourth theme resident in the early evolution of the new venture creation experience is a realization of the managerial difficulties associated with the new venture creation process. Statements describing the various business-related problems and challenges of establishing a viable new entity indicated this reality. These statements included, "The personnel problems were frequent" or "Cash flow was killing us." This resulted in a personal, reflexive assessment that oftentimes led to an acknowledgement of their lack of preparedness, lack of business adroitness, or the many mistakes made in the managerial aspects of running a business. This became tangible in the consequences and penalties caused by their lack of business knowledge. This theme was comparatively pervasive among the group and was especially interesting given that many stated that their previous job required responsibility for "all aspects" of running a division, department, or discipline. The various stories of inadequate cash flow, ineffective human resource allocation, derisory political savvy, and various other real world conundrums manifested this theme. The only seeming difference in the incidence of this theme was the description of which business area the issues surfaced. It was not their surprise at this aspect of the new venture creation process that most perplexed the participants, it was the latent realization of the importance of these aspects in the process and the resulting damage their ignorance caused.

\subsubsection{Theme 5: Decision-Making Complexities}

The fifth theme resident in the early evolution of the new venture creation experience is the realization of the complexity and enormity of decisions necessary for effectiveness in the new venture creation process. Many statements describing the general volume of decisions necessary on a daily basis, the severity of the results of their decisions, the extent of the decisions on the future of their entities, and the dependence of the firm on their ability to make crucial decisions in the business aspects of their venture revealed this theme. Most of the participants used wording such as, "Even the scientific decisions led to business decisions" or "The decisions were many and frequent." This theme was omnipresent among the group and was especially interesting given the comprehensive nature of the difficulties experienced. Various stories of uninformed accounting decisions, inadequate financial choices, mistaken human resource judgments, unapprised operational dilemmas, and other decisions indicated this theme. Most of the participants were genuinely surprised at this aspect of the new venture creation process and the underlying realization that this aspect of the new venture creation process was as important to them as it became.

\subsection{Emergent Themes in the Attainment of a Self-Sustaining Entity}

The data suggests that four categorical themes are resident in the lived experience that comprises the realization of a selfsustaining entity. This is the time at which the new venture had a dependable stream of work and the concerns over firm establishment waned. These themes are relatively consistent across the participant population and served to provide a dependable depiction of the on-going concerns intrinsic to the new venture creation experience. These themes are fascinating because they purport the significant changes in the entrepreneur caused by the phenomenon. Many of these themes significantly influenced the experience as determined by a profound reflection of the entrepreneur. The phenomenon appears to promote a reflexive appraisal of previously unrecognized abilities because of the new venture creation experience.

\subsubsection{Theme 1: The Significance of Belonging, Confidence, and Self-Esteem}

The first theme in attaining a self-sustaining entity is the significance of belonging, self-confidence, and self-esteem in the new venture creation experience. This presented itself as a recurrent and central theme in the data display. This is the point where most scientists first feel they actually belong to the group called entrepreneurs. Statements were present such as, "It was not until I saw my new innovation actually working that I came to believe that I was an entrepreneur;" or "One day, after a successful meeting with a client, he introduced me as an entrepreneur. I thought, he’s right, I am a successful entrepreneur," and, "I was hired to implement my ideas at a large landfill. They worked. When I received their check, I believed I could be successful at this.” The data suggests that during this point, reinforcement of the abilities of the entrepreneur are demonstrated in that most believed they could make the venture successful though hard work, intelligence, persistence, perseverance, drive, or determination. Statements of self-confidence included, "I finally felt my hard work was paying off" or "I finally believed I had made it." Interestingly, a recurrent theme of on-going trepidation was also present and expressed as, “...having it all come crashing down tomorrow.” Most suggested this served to strengthen their resolve. This theme was also filled with stories of initial successes, project achievements, victorious bids, competitive one-upmanship, and various other accomplishments demonstrated through company lore and assorted war stories. This generated a heightened, albeit reticent, enrichment of the confidence and self-esteem of these entrepreneurs. 


\subsubsection{Theme 2: The Movement toward Self-Actualization}

The second theme is the movement toward self-actualization in the creation of a self-sustaining entity. The accomplishments of the entrepreneur became evident and most believed they were close to achieving a successful venture. Fears and doubts diminished and most agreed the new venture creation experience, at this time, afforded them a certain freedom over time, tasks, responsibilities, and day-to-day encumbrances. Statements such as, "I reached a level of happiness" or "Contentment, I felt content" reflect this sentiment. The attainment of control over their lives expanded as shown in the ease of decision-making, fluency in more accurate and applicable solutions to dilemmas, and realizing a vision of what their future would hold. As a result, the phenomenon of the scientist-turned-entrepreneur becoming successful appeared to be attainable in whatever form the entrepreneur suggested it should take. In some cases, this is growth. In others, it is a complacent status-quo.

\subsubsection{Theme 3: The Modification of Self-Perception}

The third theme in the attainment of a self-sustaining entity is the modification of self-perception where the participants suggest an alteration in how they viewed themselves as a result of creating a self-sustaining entity. The expansion of abilities and capabilities was expressed through many statements such as, "I see myself as having grown a lot" or "I've broadened my abilities in..." This included a perceived broadening of the perspective of others including peers, coworkers, family, friends, and social acquaintances. This resulted in an extension of their focus. Many expressed this as, "I’ve become closer to my family," "I have enhanced my commitment to...," or "I am expanding into...," thus allowing for more time for family, civic undertakings, personal ministries, firm expansion, and the like. Most agreed the new venture creation experience allowed them a certain latitude and an increase of their abilities. Priorities shifted from the business and refocused toward various other issues of importance to the entrepreneur.

\subsubsection{Theme 4: Beneficence}

The fourth theme in the attainment of a self-sustaining entity is beneficence. This suggests the entrepreneur's engagement in the new venture creation process was not only beneficial to them personally, but also to others. Statements like, "I held a lot of life in my hands" or "These people depend upon me for their livelihoods," indicated this outlook. These expressions generated feelings of profound gratitude and joy for the entrepreneurs. Several viewed beneficence as a continued reason for concern for themselves, others, and their ventures. Interestingly, these entrepreneurs hold that their responsibility and significance to the livelihoods of others, is intimidating. At times, this produced additional fears, doubts, and anxieties. This apprehension is somewhat mitigated by the heightened sense of confidence produced by the creation of an entity that is self-sustaining. In this, the scientist-turnedentrepreneur appears to perceive them self as more of a leader and a director of destinies.

\section{Implications and Meaning}

The vast amount of datum presented in the foregoing sections can be synthesized. Theme synthesis is a melding and consolidation relative to the phenomenon. The data is diagramed in Figure 1. This presents a graphic portrayal of the themes resident in the creation of a new environmental venture relative to the phenomenon.

The datum can be further reduced into systematic meaning units. Reduction of the data into these meaning units is consistent with Husserl's (1931) conception that the presentation of an individual's understanding as they separately experience a shared phenomenon posits certain synthetic essential truths. These truths are conceptualized as meaning units. The following section is intended to consolidate the meaning of these structural statements relative to the phenomenon that occurs in the transition from scientist to businessperson and employee to entrepreneur.

\subsection{Evaluation of the Lived Experience: The Early Years}

The initial years of the entrepreneurial experience were filled with angst for most of the scientists-turned-entrepreneurs. The central themes resident in the early struggles of the lived experience include the realization of cultural acclimation, personal and physical difficulties, managerial difficulties, and the realization of the complexity of their decisions. These central themes reflect the lack of preparedness in the establishment of their venture. In these central themes, the scientist-turned-entrepreneur realized the enormity of their decision on themselves and others. These themes suggest meaning for the phenomenon.

First, these themes suggest an acknowledgment that the process was, in many cases, more difficult than anticipated. By overcoming the various challenges expressed as culture shocks and altered perceptions, the entrepreneur was forced to accept the role that they had chosen. In many cases, the entrepreneur was challenged by those close to them such as family, friends, and support groups. Addressing these challenges served as a fulcrum that leveraged the entrepreneur's understanding of who and what they needed to become. Moreover, many entrepreneurs admitted the physical and mental stress of these early years resulted in sleepless nights, anxiety, and additional stress on relationships. These challenges resulted in a profound realization that helped 
forge the entrepreneur's self-perception. This involved a personal understanding of the hardships resident in the transition from scientist to businessperson and employee to entrepreneur. A realization of these challenges was necessary for acculturation and is important to the phenomenon, because it forged a relationship between the person and the experience.
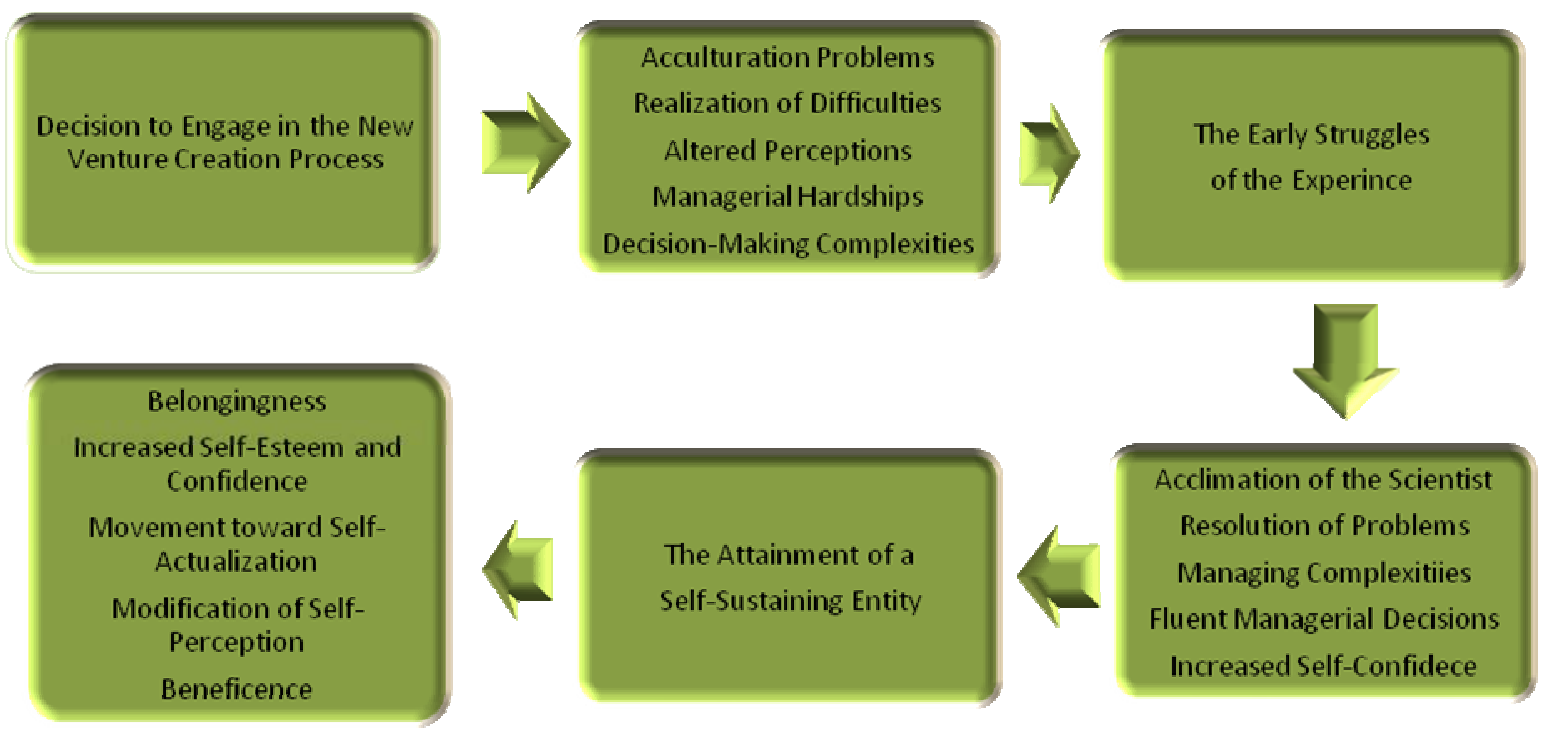

Figure 1. The New Venture Creation Process

Second, the data suggests that realizing the various managerial difficulties associated with the early years were overwhelming. These managerial difficulties include the various aspects of human resources, finance, organizational design, etc. These hardships were necessary to frame the experience for the scientist-turned-entrepreneur. Since many of the entrepreneurs foresaw such hardships prior to realizing the experience, the difficulties were not a surprise. However, the plethora of difficulties created a lasting impression of hardship due to their managerial insufficiency, created a sense of humility, and fortified their resolve to endure. This means that the realization of the enormity of managerial difficulties wrought by their inexperience became a part of their lifeworld.

Finally, all of the entrepreneurs suggested that the sheer number and intensity of decisions required of them in the early struggles of the lived experience were daunting. The decision making problems varied among the entrepreneurs and included human resource issues, financial issues, organizational design issues, political issues, and other business intricacies. Prior to engagement in the new venture, most entrepreneurs believed their technical acumen was sufficient to sustain them and that the business decision-making aspect of the venture would not be difficult or problematic. This resulted in perplexity, discomfort, and disenfranchisement once the decisions became overwhelming as the new venture creation process ensued. All of the aforementioned conundrums served to structure the means by which the environmental entrepreneur perceived the early struggles of the new venture creation experience.

\subsection{Evaluation of the Lived Experience: Sustaining the Business}

The time of the new venture creation process where a dependable stream of work was incoming and the concerns over firm establishment waned had distinct themes. The themes relating to the sustaining years of the lived experience reflect the entrepreneur's ability to prevail over the myriad of challenges of the ordeal. The result of succeeding over these challenges included achieving some of their goals, attaining a consistency of work, having time for self-reflection, and plotting a new vision for their future. These themes hold important meanings for the phenomenon in that they help define the evolution of the experience.

First, during this period, the scientists generally acknowledged the understanding that they truly belonged to the collective known as successful entrepreneurs. This is because, at this point, most came to the realization that they created a self-sustaining entity. The meaning for this is that the entrepreneurs experienced a sense of accomplishment, had come to terms with the change in their role, and had a general sense of peace with the status quo. Because of successfully prevailing over challenges, the entrepreneurs became more adroit at navigating the myriad of problems that arose. In general, many of the issues of anxiety were assuaged and the entrepreneurs were able to consider their vision for the future and the direction of their ventures.

Second, during this period, the scientists suggested the amount and complexity of business-related tasks were still excessive. However, they all came to understand that this is a part of their day-to-day existence. After a time, the scientist saw the presence of 
difficulties and business complexities as commonplace and routine in their life world. All suggested that the myriad of difficulties and complexities broadened their scope of expertise and expanded their knowledge base of the many ordinary managerial encumbrances that effect most businesses. They were able to handle these impediments in a fluent, efficient, and effective manner. They also stated they were less resistant to change and stated they had a better ability to handle and manage the decision-making process whether for personnel, organizational design, financial, or planning decisions. This means that, in addressing and overcoming these difficulties, the phenomenon provided for an increased knowledge base and a broadened skill-set for dealing with the many business-related issues.

Finally, the subsidence of the day-to-day worries and the escalation of pride in the relating of successes, achievements, and various other accomplishments demonstrated the entrepreneur sensed belongingness in the larger context of the fledgling entity. This took on an almost familial cast where the entrepreneur delighted in relating company lore, trials, and successes with aplomb. As entrepreneurs, they acknowledged an increased level of self-confidence about their abilities. The phenomenon seemed now to be personalized to the entrepreneur and their achievement. This is salient because it means that the successful transition to the new role of entrepreneur suggests the phenomenon allowed for achievement of the higher order needs of esteem to satisfy the self, selfactualization to exhibit self-fulfillment and individualism, and beneficence toward others.

\section{Essence of the Experience}

The findings, themes, and meanings provide insight into the lived experiences of environmental entrepreneurs in the new venture creation process. This study identified many associations with the existing entrepreneurship and scientific entrepreneurship literature that assists with distilling the phenomenon of transitioning from scientist to businessperson and employee to entrepreneur. The following section distills the essence of the lived experience of environmental entrepreneurs in the new venture creation experience.

The phenomenon is initially made manifest through hardship. The formative years of the undertaking are ensconced in the notion that the ordeal is difficult and is framed by mental and emotional angst as the environmental entrepreneur navigates the various business-related obstacles associated with establishing their venture. Handling these various obstacles becomes the environmental scientist's reality, solidifies their transition from employee to entrepreneur, and forms a connection with the experience. Thus, the reality is personal and professional hardship due to the complexities of the new venture creation experience. As a result, the scientist recognizes heretofore unrecognized abilities, increased self-confidence, appreciation of the intricacies of entrepreneurship, and a modification of self-perception owing to overcoming the harsh realities of the experience. The essence of the phenomenon is an enhancement of self-belief because of the ability to overcome an arduous experience.

The phenomenon is then characterized by a realization that the environmental entrepreneur has attained a self-sustaining entity. This engenders a sense of belonging and connection with the entity. The entrepreneur acknowledges the magnitude of their personal and professional growth. A consideration of the enormity of their accomplishment leads to an appreciation of their value to others. Thus, the reality of the creation of a self-sustaining entity involves the achievement of a new identity and an expanded beneficence toward others. As a result, the scientist-turned-entrepreneur realizes personal and professional growth, enhanced selfesteem, and an expanded sense of responsibility to others. The essence of the phenomenon is a profound reflexive appreciation of their accomplishments and the desire for beneficence.

\section{Conclusion}

The start-up of a new scientific entrepreneurial venture is a precarious and personal proposition. The precariousness is imbedded in the risk and elevated failure rates of such endeavors. At stake for the scientist is the profound transformation caused by the process. Scientists experience the new venture creation process differently than non-scientific entrepreneurs. Consistent with Dubinskas' (1985) findings, this is because of the distinctive educational and cultural differences that comprise their lifeworld. This research explores that concept and indicates this is because of their unpreparedness and inexperience in the various intricacies and complexities of the entrepreneurial process. Those that are successful endure many of the same experiences as other entrepreneurs. This is consistent with Bann's (2007) findings for beneficence, self-actualization, and reinforcement of self-esteem. This research suggests this is unrelated to the unique nature of the scientist because this is a part of the shared lived experience with non-scientific entrepreneurs. This research endeavored to look beyond the outward appearance of the new venture creation process to explore the meaning to the environmental entrepreneur. In so doing, this research provides insight to the essence of the phenomenon that is the transition from scientist to businessperson and employee to entrepreneur. This research enhances the existing body of knowledge of scientific entrepreneurship and provides salient information to those scientists who dare to engage in the new venture creation process.

\section{Assumptions and Limitations}

The methodology of this research carries with it certain assumptions. Qualitative research is found in natural settings that illustrate human behavior where quantitative methodology requires the inclusion of hypotheses or theories (Creswell, 2002). The researcher 
maintains a prominent role in qualitative data collection by recording descriptive words or images rather than numbers or statistics. These assumptions, while implied by the methodology, are provided to maintain transparency in several of the fundamental assumptions that guide this research.

Certain limitations are also inherent in this work. The study is first limited by time. The relevance of the 2009 time period, chronologic setting, and conditions of the socio-economic environment might limit the relevance of this research to other time periods. In addition, this research included only environmental entrepreneurs. It should not be assumed that all entrepreneurs, scientific or otherwise, behave similarly. Further, this study is limited by place. The experiences and perspectives of the participant population from Ohio may or may not provide a significant representation of other populations. Finally, the scope of this research included only autonomous founders of environmental entrepreneurial ventures and those who were not autonomous founders were not evaluated during this study.

Finally, the philosophy of this research was a lived experience of the participant's new venture creation process. Phenomenological inquiry aims to elucidate the essence of a phenomenon as understood by the participants and analyzed by the researcher. This philosophy presents two limitations. First, participants must willingly, openly, and honestly discuss their experiences. Failure to do so will affect the study. Second, since the researcher determines themes and extracts the essence of the experience, the researcher's ability to effectively do this also affects the study.

\section{References}

Ahn, M. J. 2008. Building a conducive environment for life science-based entrepreneurship and industry clusters. Journal of Commercial Biotechnology, Vol. 14, No. 1, pp. 20-31.

Bann, C. L. 2007. Entrepreneurial lives: A phenomenological study of the lived experience of the entrepreneur, including the influence of values, beliefs, attitudes, and leadership in the entrepreneurial journey (Doctoral Dissertation, Capella University). Retrieved from http://gateway.proquest.com/openurl\%3furl_ver=Z39.88-2004\%26res_dat=xri:pqdiss

\%26rft_val_fmt=info:ofi/fmt:kev:mtx:dissertation\%26rft_dat=xri:pqdiss:3244893.

Bell, C. G., \& McNamara, J. E. 1991. High tech ventures: The guide for entrepreneurial success. Reading, MA: Addison-Wesley. Burns, T., \& Stalker, G. M. 1966. The Management of Innovation. London: Tavistock Publications.

Cooper, A. C., Folta, T.B., \& Woo, C. 1995. Entrepreneurial information search. Journal of Business Venturing, Vol. 10, pp. 107120.

Creswell, J. W. 2002. Research design: Qualitative and quantitative approaches. Thousand Oaks, CA: Sage.

Creswell, J. W. 2007. Qualitative inquiry and research design. Thousand Oaks, CA: Sage Publications.

Creswell, J. W., \& Miller, D. L. 2000. Determining validity in qualitative inquiry. Theory into Practice, Vol. 39, No. 3, pp. 124-

131.

Danielson, L. E. 1960. Characteristics of engineers and scientists, significant for their utilization and motivation. Ann Arbor, MI: University of Michigan Press.

Davis, S., Haltiwanger, J., Jarmin, R., Krizan, C.J., Javier, M., Nucci, A., and Sandusky, K. 2007. Measuring the Dynamics of Young and Small Businesses: Integrating the Employer and Nonemployer Universes. NBER Working paper. No. 13226. Forthcoming in Timothy Dunne, J. Bradford Jensen, and Mark J. Roberts (eds.), Producer dynamics: new evidence from micro data. Retrieved on April 5, 2010 from http://www.kauffman.org/uploadedFiles/TurmoilandGrowth060208.pdf

Davis, S.J., Haltiwanger, J., and Jarmin, R. 2008. Turmoil and growth: Young businesses, economic churning, and productivity gains. The Kauffman Foundation. Retrieved from http://www.kauffman.org/uploadedFiles/TurmoilandGrowth060208.pdf on April 5, 2010.

Denzin, N. K. 1978. Sociological methods: A sourcebook ( ${ }^{\text {nd }}$ ed.). New York, NY: McGraw-Hill Publications.

Dubinskas, F. A. 1985. The culture chasm: Scientists and managers in genetic engineering firms. Technology Review, 88.

Gaebler Ventures 2009. Scientist Entrepreneurs. Gaebler.com. Retrieved on April 5, 2010 from http://www.gaebler.com/Entrepreneurship-for-Scientists.htm.

Headd, B. 2002. Refining business success: Distinguishing between closure and failure. U. S. Small Business Administration. Washington, D. C.: Office of Advocacy.

Hochberg, S., \& Cohen, S. 2006. UN Environmental Programme. Brown University. Retrieved from http://www.busun.net/committees/guides/UNEP.pdf on January 14, 2009.

Husserl, E. 1931. Ideas: General introduction to pure phenomenology. London: George Allen and Unwin.

Kvale, S. 1996. Interviews: An introduction to qualitative research interviewing. Thousand Oaks, CA: Sage Publications.

Lewin, K. 1935. A dynamic theory of personality. New York, NY: Harper and Rowe.

Litvak, A. I., \& Maule, C. J. 1973. Some characteristics of successful technical entrepreneurs in Canada. IEEE Transactions on Engineering Management, Vol. 20, No. 3, pp. 62-68.

Maslow, A. H. 1954. Motivations and personality (1st Ed.) New York, NY: Harper and Rowe Publishers.

McClelland, D. 1961. The achieving society. Princeton, NJ: Van Nostrand.

Miles, M. B., \& Huberman, A. M. 1994. Qualitative data analysis: An expanded sourcebook (2nd ed.). Thousand Oaks, CA: Sage Publications. 
Kenney, M. 1986. Schumpeterian innovation and entrepreneurism: A case study of the U. S. biotechnology industry. Research Policy, Vol. 15, No. 1, pp. 21-33.

Niemi, R. J. 1993. Towards a theory of interprofessional collaboration in the commercialization of biotechnology. Unpublished Dissertation, Case Western Reserve University: Cleveland, Ohio; AAT 9406262.

Moss-Kanter, R. 1989. When giants learn to dance. New York, NY: Simon and Schuster.

Phillips, D. J., \& Zuckerman, E. W. 2001. Middle-status conformity: Theoretical restatement and empirical demonstration in two markets. American Journal of Sociology, Vol. 107, pp. 379-429.

Plato 1982. Plato's republic. New York, NY: Oxford University Press.

Roberts, E. B., \& Wainer, H. A. 1971. Some characteristics of technical entrepreneurs. IEEE Transactions on Engineering Management, Vol. 18, No. 3, pp. 100-109.

Samsom, K. J. 1990. Scientists as entrepreneurs, organizational performance in scientist-started new ventures. Norwell, MA: Kluwer Academic Publishers.

Schuster, S. 2008. Obama still pledging green jobs to help ailing economy. The Green Report. Retrieved on January 13, 2009 from http://www.greendaily.com/2008/11/26/obama-still-pledging-green-jobs-to-help-ailing-economy.

Sindermann, C. J. 1982. Winning the games scientists play. New York, NY: Plenum Press.

Stuart, T., Ding, W., \& Waverly, W. (2006). When do scientists become entrepreneurs? The social structural antecedents of commercial activity in the academic life sciences. American Journal of Sociology, Vol. 112, No. 1, 97-144.

Venkataraman, S. 1997. The distinctive domain of entrepreneurship. In Katz, J.A. (ed.), Advances in Entrepreneurship: Firm Emergence and Growth, pp. 119-138.

Zucker, L. G. 1998. Entrepreneurs, star scientists, and biotechnology: Entrepreneurial intentions of bioscientists and biotechnologists. National Bureau of Economic Research Reporter, Vol. 7, No. 4, pp. 7-11.

\section{Biographical notes}

Dr. William Racine is a primary Professor at Malone University in Canton, Ohio instructing and developing both online and ground classes. His work specializes in entrepreneurship, specifically scientific entrepreneurship. Dr. Racine also teaches in the graduate program for Organizations and Leadership. He received an MBA from Kent State University (OH) in 1986 and a Ph. D. from Capella University (MN) in 2009. Dr. Racine has been published in several peer-reviewed publications since that time. Since 1989, he started and operated five scientific entrepreneurial ventures. Dr. Racine has been an environmental consultant operating his own environmental firm since 1989.

Received May 2010

Accepted August 2010

Final acceptance in revised form September 2010 